\title{
Challenges and unmet needs in basal insulin therapy: lessons from the Asian experience
}

This article was published in the following Dove Press journal: Diabetes, Metabolic Syndrome and Obesity:Targets and Therapy

\author{
Wing Bun Chan' \\ Jung Fu Chen ${ }^{2}$ \\ Su-Yen Goh ${ }^{3}$ \\ Thi Thanh Huyen $\mathrm{Vu}^{4}$ \\ Iris Thiele Isip-Tan ${ }^{5}$ \\ Sony Wibisono Mudjanarko ${ }^{6}$ \\ Shailendra Bajpai ${ }^{7}$ \\ Maria Aileen Mabunay ${ }^{7}$ \\ Pongamorn Bunnag ${ }^{8}$ \\ 'Qualigenics Diabetes Centre, Hong \\ Kong SAR, People's Republic of China; \\ ${ }^{2}$ Division of Metabolism, Department \\ of Internal Medicine, Kaohsiung \\ Chang Gung Memorial Hospital, \\ Chang Gung University College \\ of Medicine, Kaohsiung, Taiwan; \\ ${ }^{3}$ Department of Endocrinology, \\ Singapore General Hospital, \\ Singapore; ${ }^{4}$ Out-patient Department \\ and Department of Internal Medicine, \\ National Geriatric Hospital, Hanoi \\ Medical University, Hanoi,Vietnam; \\ ${ }^{5}$ Section of Endocrinology, Diabetes \\ and Metabolism, University of the \\ Philippines-Philippine General \\ Hospital, Manila, Philippines; ' ${ }^{6}$ iabetes \\ and Nutrition Centre, Dr. Soetomo \\ Hospital, School of Medicine Airlangga \\ University, Surabaya, Indonesia; ${ }^{7}$ Sanofi, \\ Singapore; ${ }^{8}$ Department of Medicine, \\ Faculty of Medicine, Ramathibodi \\ Hospital, Mahidol University, Bangkok, \\ Thailand
}

Correspondence: Pongamorn Bunnag Department of Medicine, Ramathibodi Hospital, 270 Thung Phaya Thai, Ratchathewi, Bangkok 10400, Thailand Tel $+662201 \quad 1647$

Fax +66 220I 1647

Email pongamornb@gmail.com

\begin{abstract}
Basal insulin therapy can improve glycemic control in people with type 2 diabetes. However, timely initiation, optimal titration, and proper adherence to prescribed basal insulin regimens are necessary to achieve optimal glycemic control. Even so, glycemic control may remain suboptimal in a significant proportion of patients. Unique circumstances in Asia (eg, limited resources, management of diabetes primarily in nonspecialist settings, and patient populations that are predominantly less educated) coupled with the limitations of current basal insulin options (eg, risk of hypoglycemia and dosing time inflexibility) amplify the challenge of optimal basal insulin therapy in Asia. Significant progress has been made with long-acting insulin analogs (insulin glargine $100 \mathrm{units} / \mathrm{mL}$ and insulin detemir), which provide longer coverage and less risk of hypoglycemia over intermediate-acting insulin (Neutral Protamine Hagedorn insulin). Furthermore, recent clinical evidence suggests that newer long-acting insulin analogs, new insulin glargine 300 units $/ \mathrm{mL}$ and insulin degludec, may address some of the unmet needs of current basal insulin options in terms of risk of hypoglycemia and dosing time inflexibility. Nevertheless, more can be done to overcome barriers to basal insulin therapy in Asia, through educating both patients and physicians, developing better patient support models, and improving accessibility to long-acting insulin analogs. In this study, we highlight the unique challenges associated with basal insulin therapy in Asia and, where possible, propose strategies to address the unmet needs by drawing on clinical experiences and perspectives in Asia.
\end{abstract}

Keywords: insulin titration, insulin detemir, insulin glargine, insulin degludec, patient education

\section{Introduction}

Basal insulin refers to the low, but relatively constant level of insulin vital for glucose regulation and maintaining normoglycemia during periods of fasting (eg, overnight and between meals). For most people with diabetes, progressive deterioration of $\beta$-cell function eventually results in a need for basal insulin supplementation to maintain glycemic control. The goal of basal insulin therapy is simple - to approximate physiological basal insulin activity by providing a sustained release of insulin over an extended period of time.

Intermediate-acting insulin (eg, Neutral Protamine Hagedorn [NPH] insulin) and long-acting insulin analogs (eg, insulin glargine $100 \mathrm{U} / \mathrm{mL}$ [Gla-100] and insulin detemir) are commonly administered for basal insulin therapy. This exogenous provision of basal insulin is crucial to achieve and maintain normoglycemia in individuals with diabetes, especially when tight glycemic control is desired. In clinical practice, basal insulins are typically administered in combination with oral hypoglycemic agents or rapid-acting insulins to achieve sufficient glycemic control throughout the day. ${ }^{1}$ 
Basal insulins provide a means to control fasting plasma glucose. However, timely insulin initiation, dose optimization, and proper adherence to prescribed insulin regimens are necessary to achieve optimal glycemic control. Individualization of therapy regimens according to patient lifestyles is necessary to achieve the optimal balance between glycemic control, adverse effects, and impact on patient lifestyle. In Asia and other regions with many developing countries, unique challenges exist in the form of limited resources, management of diabetes primarily in nonspecialist settings, and patient populations that are predominantly less educated.

This article aimed at highlighting the unique challenges associated with basal insulin therapy in Asia and, where possible, proposing strategies to address these unmet needs by drawing on clinical experiences and perspectives in Asia.

\section{Challenges in basal insulin therapy Delay in insulin initiation}

In the face of a worsening glycemic profile $(\mathrm{HbA} 1 \mathrm{c}>58$ $\mathrm{mmol} / \mathrm{mol}[>7.5 \%]$ ), despite maximal oral therapy, the International Diabetes Federation guidelines for diabetes management recommend initiating insulin in the form of basal insulin therapy. ${ }^{1}$ Clinical practice guidelines in Asia follow international recommendations closely. ${ }^{2-8}$ Depending on individual patient characteristics, glycemic profile, the risk of hypoglycemia, and the presence of comorbidities, basal insulin therapy may be initiated after failure to achieve glycemic targets with single-, dual-, or triple-oral therapy. Failure to commence basal insulin therapy despite inadequate glycemic control with 3 oral agents may reasonably be considered an undue delay in insulin initiation.

Notably, the findings of international and Asian studies (eg, SOLVE, ${ }^{9}$ INSTIGATE, ${ }^{10}$ and FINE-Asia ${ }^{11,12}$ ) demonstrate some divergence between treatment guidelines and initiating insulin in real-world clinical practice. Inertia in initiating insulin therapy is a troubling phenomenon. Large-scale observational studies with predominantly Western cohorts have reported high levels of $\mathrm{HbA1c}$ prior to insulin initiation $\left(\right.$ mean $\mathrm{HbA} 1 \mathrm{c}=74 \mathrm{mmol} / \mathrm{mol}[8.9 \%],{ }^{9} 81 \mathrm{mmol} / \mathrm{mol}$ $[9.6 \%],{ }^{13}$ and $85 \mathrm{mmol} / \mathrm{mol}\left[9.9 \%{ }^{10}\right)$. Despite no appreciable improvement in glycemic control, time to onset of insulin therapy was observed to have increased over the years. ${ }^{14}$ Basal insulin initiation also appears to be delayed in Asia. In the 11-country FINE-Asia study involving 2,679 people starting basal insulin therapy, mean duration of diabetes was 9.3 years and baseline $\mathrm{HbAlc}$ was $84 \mathrm{mmol} / \mathrm{mol}(9.8 \%) .{ }^{11}$ Baseline $\mathrm{HbA} 1 \mathrm{c}$ was highest in patients from Southeast Asia (defined as Bangladesh, Hong Kong, Indonesia, Singapore, and
Vietnam; mean $\mathrm{HbAlc}=91 \mathrm{mmol} / \mathrm{mol}[10.5 \%])$, followed by Thailand and Taiwan (mean HbAlc $=88 \mathrm{mmol} / \mathrm{mol}$ [10.2\%] for both). ${ }^{12}$ The high prevalence of diabetes complications in insulin-naïve patients is of still greater concern, ${ }^{15}$ which is indicative of long periods of poor glucose control.

\section{Patient barriers}

Patient resistance to insulin therapy has been described in a number of studies. In surveys, patients have reported worries about starting insulin therapy; ${ }^{16}$ over one quarter of the patients in one survey expressed unwillingness to use insulin even when prescribed. ${ }^{17}$ The prevalence of insulin therapy refusal appears to be even higher in less educated Asian cohorts. In an insulin-naïve Asian cohort, most of whom did not have tertiary education (88.5\%), 7 of every 10 patients were unwilling to start on insulin therapy. ${ }^{18}$

A variety of factors contribute to this resistance; needlephobia, doubts about the actual benefits of insulin, misconceptions regarding insulin as a terminal treatment or on developing insulin dependence, and perceived complexities in using insulin. ${ }^{16,17,19,20}$

\section{Physician barriers}

Physician barriers contribute to clinical inertia in initiating insulin therapy. Physicians are concerned about the efficacy, safety, and flexibility of insulin therapy. Even on insulin therapy, most physicians $(87.6 \%)$ report that many patients do not have adequate glucose control. ${ }^{21}$ As physician concern about hypoglycemia limits treatment aggressiveness, there is a need for insulin formulations with a greater dosing flexibility and a better safety profile. ${ }^{21}$

In many developing countries in Asia, delays in basal insulin initiation may arise due to physician unfamiliarity with diabetes management and guidelines. Access to diabetes care and medications may also be limited in less developed regions. ${ }^{22}$ Nonetheless, basal insulin initiation in both urban and rural areas appears inadequate; among Chinese patients, baseline $\mathrm{HbA} 1 \mathrm{c}$ values prior to insulin initiation were 86 $\mathrm{mmol} / \mathrm{mol}(10.0 \%)$ and $80 \mathrm{mmol} / \mathrm{mol}(9.5 \%)$ in rural and urban areas, respectively. ${ }^{15}$

\section{Infrastructural barriers}

In many parts of Asia, the challenge of initiating insulin therapy is amplified by the lack of supportive healthcare infrastructures. Rates of insulin usage are generally low across the region (Table 1) - likely a result of several resource constraints: 1) low numbers of endocrinologists compared with the growing number of people with diabetes (Table 1); 
Table I Number of adults with diabetes, endocrinologists, and estimated rates of insulin usage by territory

\begin{tabular}{llll}
\hline Territory & $\begin{array}{l}\text { Adults } \\
\text { (uncertainty range) }^{\mathbf{7 3}}\end{array}$ & $\begin{array}{l}\text { Number of } \\
\text { endocrinologists }\end{array}$ & $\begin{array}{l}\text { Estimated rate of insulin usage } \\
\text { (insulin and insulin analogs) }\end{array}$ \\
\hline Hong Kong & $582.5(515.8-686.5)$ & 104 & $21.8 \%^{74}$ \\
Indonesia & $10,021.4(8,736.6-10,882.8)$ & 101 & Not reported \\
Philippines & $3,506.5(2,702.3-4,584.6)$ & 202 & $42.0 \%^{75}$ \\
Singapore & $541.6(466.4-613.3)$ & 105 & Not reported \\
Taiwan & $1,781.1(1,386.6-2,293.8)$ & -600 & $27.3 \%^{76}$ \\
Thailand & $4,025.1(2,965.6-4,633.2)$ & -250 & $25.3 \%^{77}$ \\
Vietnam & $3,509.1(2,582.5-5,501.2)$ & -300 & Not reported \\
\hline
\end{tabular}

Note: ${ }^{2} 20-79$ years old.

2) consultations are usually too brief to educate patients on using insulin safely and effectively; 3 ) shortage of diabetes educators, nurses, and diabetes care teams to provide patient support (Table 2); 4) unavailability of insulin or insulin analogs in rural regions (Table 2); and 5) insufficient coverage of longer-acting insulin analogs, syringes, needles, glucometers, and glucose test strips by medical insurance or public subsidies (Table 2).

\section{Insufficient dose titration}

Initiation of insulin therapy does not guarantee adequate glycemic control. Fine-tuning of insulin doses guided by fasting glucose measurements is necessary to maximize the benefits of basal insulin therapy. The International Diabetes Federation guidelines recommend a self-titration regimen, starting with a low dose of insulin (usually $10 \mathrm{U} /$ day) and increasing this dose by 2 units every 3 days until the premeal blood glucose target of $<6.0 \mathrm{mmol} / \mathrm{L}(<108 \mathrm{mg} / \mathrm{dL})$ is reached. ${ }^{1}$ Alternatively, if frequent contact with a healthcare professional is possible, insulin dose may also be titrated using a scaled algorithm. ${ }^{1}$

Glycemic control remains poor in many patients on basal insulin therapy. Only one third of Asian patients achieved HbA1c $<53 \mathrm{mmol} / \mathrm{mol}(<7 \%)$ after 6 months of basal insulin therapy. ${ }^{11}$ This achievement was lowest in Taiwan (7.4\%), followed by Korea (13.1\%), Thailand (15.2\%), and Southeast Asia (26.4\%). ${ }^{12}$ Poor glycemic control despite active insulin therapy suggests an inadequate dose titration. Dose titration in the FINE-Asia registry study was minimal, ${ }^{11}$ with slight variations between the cohorts of individual Asian countries. ${ }^{12}$ Change in total daily insulin dose from baseline to 6 months after the initiation of basal insulin ranged from $0.83 \mathrm{U}$ in Korea to $6.04 \mathrm{U}$ in Thailand. ${ }^{12}$ Similarly, in the A1chieve study, there were limited adjustments of basal insulin doses over 6 months in China, South Asia, and East Asia. ${ }^{23}$ In addition to setting less stringent glycemic goals, physicians in Asia also appear to take a conservative approach to insulin titration. ${ }^{11}$ As a result, insufficient insulin dose titration is a common cause of persistent hyperglycemia in many patients.

\section{Concerns about hypoglycemia}

Symptoms of hypoglycemia typically surface when blood glucose levels are in the range of 3.4-3.6 mmol/L (61.2-64.8 $\mathrm{mg} / \mathrm{dL}) .{ }^{24}$ During episodes of hypoglycemia, patients may experience acute symptoms such as tachycardia, sweating, and in severe cases confusion, coma, or even death. ${ }^{25}$ Nocturnal hypoglycemia is particularly worrying as patients may be oblivious to the symptoms of low blood glucose during sleep. ${ }^{26}$ If left unmanaged, the long-term effects of hypoglycemia are grave - reduced working capacity, lower quality of life, and increased risk of cardiovascular diseases. ${ }^{27}$

In the USA, nearly 1 in 4 (22.9\%) type 2 diabetes-related hospital admissions were due to hypoglycemia. ${ }^{28}$ Indeed, hypoglycemia is a common treatment-associated complication in patients treated with insulin. ${ }^{29}$ Fear of hypoglycemia is common among patients, ${ }^{17}$ and the experience of hypoglycemic episodes may prompt patients to reduce their insulin doses. As severe hypoglycemia is associated with major vascular events and increased mortality, ${ }^{27}$ physicians are also cautious when it comes to intensifying treatment to achieve tight glycemic control. ${ }^{21}$ Given these concerns, hypoglycemia is a major limiting factor to achieving glycemic targets with basal insulin therapy. ${ }^{24}$

There are considerable differences in the risk of hypoglycemia between currently available basal insulins (NPH insulin, Gla-100, and insulin detemir). Evidence from both long-term controlled trials and real-life clinical practice demonstrated that long-acting insulin analogs (Gla-100 and insulin detemir) carry a lower risk of hypoglycemia compared with the intermediate-acting insulin (NPH insulin). ${ }^{30,31}$ Nonetheless, the burden of hypoglycemia continues to be a barrier to ideal glycemic control in patients on long-term therapy with basal insulin analogs. ${ }^{32}$ Until better insulin formulations with lower risks of hypoglycemia become widely accessible, 
Table 2 Diabetes-related resources by territory

\begin{tabular}{|c|c|c|c|c|}
\hline Territory & $\begin{array}{l}\text { Clinical practice } \\
\text { guidelines on insulin } \\
\text { titration }\end{array}$ & $\begin{array}{l}\text { Diabetes support teams } \\
\text { and education programs }\end{array}$ & $\begin{array}{l}\text { Availability of insulins } \\
\text { for basal insulin } \\
\text { therapy }\end{array}$ & $\begin{array}{l}\text { Subsidy status of consumables and } \\
\text { insulins for basal insulin therapy }\end{array}$ \\
\hline Hong Kong & $\begin{array}{l}\text { The Hong Kong } \\
\text { Reference Framework for } \\
\text { Diabetes Care for Adults } \\
\text { in Primary Care Settings } \\
2013 \text { recommends an } \\
\text { initial insulin dose of I0 } \\
\text { units/day ( } 0.1-0.2 \text { units/ } \\
\mathrm{kg} \text { per day), followed by } \\
\text { titration every I- } 2 \text { weeks } \\
\text { according to Hemastix } \\
\text { monitoring. } \\
\text { However, in clinical } \\
\text { practice, there is no } \\
\text { standardized way of } \\
\text { titration, and it is often } \\
\text { up to the discretion of } \\
\text { individual physicians and } \\
\text { diabetes nurses. }\end{array}$ & $\begin{array}{l}\text { There are no formal diabetes } \\
\text { education programs. } \\
\text { However, certified diabetes } \\
\text { educators are available } \\
\text { in the public sector to } \\
\text { educate patients on insulin } \\
\text { administration and to support } \\
\text { subsequent titration. }\end{array}$ & $\begin{array}{l}\mathrm{NPH} \text { insulin, Gla-100, } \\
\text { and insulin detemir are } \\
\text { available in all hospitals. }\end{array}$ & $\begin{array}{l}\text { Fully subsidized: NPH insulin is fully } \\
\text { subsidized. Gla-100 and insulin detemir } \\
\text { are fully subsidized only if patients meet } \\
\text { certain criteria (eg, frequent admission } \\
\text { for hypoglycemic episodes and the } \\
\text { presence of cardiovascular disease) } \\
\text { Partially subsidized: none } \\
\text { Partially subsidized for a selected } \\
\text { group of patients who require financial } \\
\text { assistance: none } \\
\text { Nonsubsidized: needles, syringes, and } \\
\text { glucometers }\end{array}$ \\
\hline Indonesia & $\begin{array}{l}\text { The Consensus } \\
\text { Management and } \\
\text { Prevention of Type } \\
2 \text { Diabetes Mellitus } \\
\text { in Indonesia } 201 \text { I } \\
\text { recommends the addition } \\
\text { of } 2-4 \text { units of basal } \\
\text { insulin every } 3-4 \text { days } \\
\text { until glycemic target is } \\
\text { achieved. }^{8}\end{array}$ & $\begin{array}{l}\text { The availability of certified } \\
\text { diabetes educators differs } \\
\text { between cities, and they } \\
\text { are concentrated mostly } \\
\text { in larger cities. Where } \\
\text { certified diabetes educators } \\
\text { are available, they provide } \\
\text { patient education on insulin } \\
\text { administration and support } \\
\text { subsequent titration. }\end{array}$ & $\begin{array}{l}\text { NPH insulin, Gla-100, } \\
\text { and insulin detemir are } \\
\text { available in all public and } \\
\text { private hospitals and } \\
\text { in medical community } \\
\text { outlets in rural areas. }\end{array}$ & $\begin{array}{l}\text { Fully subsidized: NPH insulin, } \\
\text { Gla-100, and insulin detemir are fully } \\
\text { subsidized for both type I and } \\
\text { type } 2 \text { diabetes } \\
\text { Partially subsidized: none } \\
\text { Partially subsidized for a selected } \\
\text { group of patients who require financial } \\
\text { assistance: none } \\
\text { Nonsubsidized: Needles, syringes, } \\
\text { glucometers, and glucose test strips }\end{array}$ \\
\hline Philippines & $\begin{array}{l}\text { The Philippine Practice } \\
\text { Guidelines on the } \\
\text { Diagnosis and Management } \\
\text { of Diabetes Mellitus } \\
2014 \text { does not specify a } \\
\text { standardized algorithm } \\
\text { for titration as response } \\
\text { depends on the individual } \\
\text { patient's metabolism and } \\
\text { the type of insulin taken. }^{5}\end{array}$ & $\begin{array}{l}\text { Certified diabetes educators } \\
\text { are available during outpatient } \\
\text { visits and prior to hospital } \\
\text { discharge to provide } \\
\text { patient education on insulin } \\
\text { administration and titration. } \\
\text { However, most patients still } \\
\text { depend on their doctors for } \\
\text { subsequent titration of insulin } \\
\text { doses. }\end{array}$ & $\begin{array}{l}\text { NPH insulin, Gla-I00, } \\
\text { and insulin detemir } \\
\text { are available in most } \\
\text { private hospitals. In } \\
\text { government hospitals } \\
\text { under the Department } \\
\text { of Health, NPH insulin } \\
\text { is available, but Gla-100 } \\
\text { and insulin detemir are } \\
\text { not available. } \\
\text { NPH insulin, Gla-I00, } \\
\text { and insulin detemir can } \\
\text { be purchased from drug } \\
\text { stores in major cities. } \\
\text { However, access to insulin } \\
\text { tends to be difficult in } \\
\text { geographically isolated and } \\
\text { disadvantaged areas of the } \\
\text { Philippines. }\end{array}$ & $\begin{array}{l}\text { Fully subsidized: NPH insulin is fully } \\
\text { subsidized by the Philippine Health } \\
\text { Insurance Corporation for inpatient care } \\
\text { Partially subsidized: none } \\
\text { Partially subsidized for a selected } \\
\text { group of patients who require financial } \\
\text { assistance: NPH insulin (assisted by a } \\
\text { PSEDM program). NPH insulin, Gla-I00, } \\
\text { and insulin detemir for indigent patients } \\
\text { (depending on availability, subsidized } \\
\text { by the Philippine Charity Sweepstakes } \\
\text { Office) } \\
\text { Nonsubsidized: NPH insulin for } \\
\text { outpatient care. Gla-I00 and insulin } \\
\text { detemir for both inpatient and outpatient } \\
\text { care. Needles, syringes, glucometers, and } \\
\text { glucose test strips }\end{array}$ \\
\hline
\end{tabular}


Table 2 (Continued)

\begin{tabular}{|c|c|}
\hline Territory & $\begin{array}{l}\text { Clinical practice } \\
\text { guidelines on insulin } \\
\text { titration }\end{array}$ \\
\hline Singapore & $\begin{array}{l}\text { The Singapore Clinical } \\
\text { Practice Guidelines } \\
\text { for Diabetes Mellitus } \\
2014 \text { does not specify a } \\
\text { standardized algorithm } \\
\text { for titration. }{ }^{7} \text { In clinical } \\
\text { practice, titration is often } \\
\text { up to the discretion of } \\
\text { individual physicians and } \\
\text { diabetes nurses. }\end{array}$ \\
\hline Taiwan & $\begin{array}{l}\text { The DAROC Clinical } \\
\text { Practice Guidelines for } \\
\text { Diabetes Care } 2015 \\
\text { recommends a starting } \\
\text { basal insulin dose of } \\
0.1-0.2 \mathrm{U} / \mathrm{kg}^{6}{ }^{6} \text { The choice } \\
\text { of the titration scheme } \\
\text { is based on physician's } \\
\text { clinical judgment on } \\
\text { individual patients' } \\
\text { condition. }\end{array}$ \\
\hline
\end{tabular}

\section{Diabetes support teams and education programs}

Public sector institutions have multidisciplinary diabetes centers with access to certified diabetes educators (nurse only) and dietitians. The diabetes centers provide initial patient education on insulin administration faceto-face and provide ongoing support via phone, e-mail, fax, and face-to-face consultations.

Over 5,000 certified diabetes educators are available in Taiwan. Certified diabetes educators provide patient education on insulin administration and support subsequent titration.
$\mathrm{NPH}$ insulin, Gla-I00, and insulin detemir are available in all hospitals.

$\mathrm{NPH}$ insulin is available in all hospitals. Gla-100 and insulin detemir are available in university hospitals and regional center hospitals but are usually not available in community hospitals situated in rural regions. hospitals or large hospitals) to educate patients on insulin administration.

\section{Vietnam The Vietnamese}

Association of Diabetes and Endocrinology guidelines do not specify a standardized algorithm for titration. In clinical practice, most physicians refer to the ADA/EASD or AACE guidelines for insulin dose titration.
Individual hospitals and institutes have their own diabetes education programs to provide patient education on insulin administration and support subsequent titration. There is no formal certification program for diabetes educators.
$\mathrm{NPH}$ insulin is available in all hospitals. Gla-100 and insulin detemir are available in the hospitals of major cities, but unavailable in local and provincial hospitals situated in rural regions.
Subsidy status of consumables and insulins for basal insulin therapy

Fully subsidized: none

Partially subsidized: NPH insulin (if purchased through government-linked primary healthcare clinics, known as polyclinics)

Partially subsidized for a select group of patients who require financial assistance (scheme: Medication Assistance Fund): Gla-I00 and insulin detemir

Nonsubsidized: Gla-100, insulin detemir, syringes, needles, pen needles, glucometers, and glucose test strips

Fully subsidized (Scheme: National Health Insurance): NPH insulin, Gla-100, insulin detemir, syringes, needles and insulin pens for all diabetes patients. Glucose test strips only for patients with type I diabetes

Partially subsidized: none

Partially subsidized for a selected group of patients who require financial assistance: none

Nonsubsidized: Glucometers and glucose test strips (except for type I diabetes) Fully subsidized: NPH insulin, glucose test strips (type I diabetes only, subsidized only in some teaching hospitals, up to 3 strips/day), Gla-I00 (type I diabetes only)

Partially subsidized: none

Partially subsidized for a selected group of patients who require financial assistance: none

Nonsubsidized: Insulin detemir (for both type I and 2 diabetes), Gla- 100 (type 2 diabetes), syringes, needles, pen needles, glucometers, and glucose test strips (type 2 diabetes)

Fully subsidized: none

Partially subsidized (up to US\$70/ prescription): NPH insulin, Gla-100, and insulin detemir

Partially subsidized for a selected group of patients who require financial assistance: none

Nonsubsidized: syringes, needles, pen needles, glucometers, and glucose test strips

Abbreviations: AACE, American Association of Clinical Endocrinologists; ADA/EASD, American Diabetes Association/European Association for the Study of Diabetes; DAROC, Diabetes Association of the Republic of China; Gla-100, glargine 100 units/mL; NPH, Neutral Protamine Hagedorn; PSDEM, Philippine Society Endocrinology, Diabetes and Metabolism. 
the risk of hypoglycemia will continue to impede optimal dose titration in patients on basal insulin therapy.

\section{Uncertainties regarding insulin titration}

Clinical practice guidelines for dose increments and frequency of titration for basal insulin vary between countries. ${ }^{33,34} \mathrm{In}$ Asia, some local diabetes management guidelines do not provide a standardized prescriptive algorithm for insulin dose titration (Table 2) ${ }^{2-8}$ To guide titration decisions, some physicians have adopted the basal insulin titration algorithms recommended by the American Diabetes Association/European Association for the Study of Diabetes or American Association of Clinical Endocrinologists guidelines. ${ }^{33,34}$ In clinical practice, titration is often up to the discretion of individual physicians, and the choice of the titration scheme is based on physician's clinical judgment on individual patients' condition. Especially in less developed regions in Asia, the lack of physician knowledge and patient support and poor application of titration algorithms in insulin titration approaches may cause unnecessary complexities in dose adjustment, leading to unintentional dosing errors or insufficient dose titration.

\section{Infrequent clinic visits}

Basal insulin dose titration requires physician advice and is usually done in conjunction with a healthcare provider. Although patients can be taught self-titration of insulin, many patients in Asian countries are unable or unwilling to selftitrate, resulting in heavy reliance on physicians' clinical judgment for insulin dose adjustments. Physician-managed titration requires close patient monitoring and regular clinic visits or contact. Unfortunately, visits to clinics can be infrequent due to low patient awareness of the need for follow-up, high costs of multiple clinic visits, and/or shortage of healthcare professionals and medical infrastructure in less developed regions. As a result, many patients who titrate insulin only during clinic visits are likely to be administering basal insulin doses that are far too low for adequate glycemic control. The lack of structured patient education and patient support programs in Asia (Table 2) further amplifies the challenge of optimal insulin dose titration for patients with type 2 diabetes in the region.

\section{Adherence and persistence with therapy}

Adherence to insulin therapy is generally poor, with $\sim 1$ in 3 patients reporting insulin omission/nonadherence. ${ }^{21}$ The majority of physicians $(72.5 \%)$ also reported patient deviation from prescribed insulin regimens. ${ }^{21}$ Poor adherence to insulin therapy is associated with lower glycemic control and adverse outcomes. Two studies independently reported significantly higher HbAlc levels in patients who missed insulin injections compared with those who never missed a dose. ${ }^{35,36}$ In addition, hospitalization and mortality were increased in the cohort of nonadherent patients. ${ }^{36}$

Low treatment persistence is another major barrier. ${ }^{37-39}$ A retrospective database study in the USA indicated that the probability of early discontinuation of insulin is extremely high (41.0\% in the first month) and increases over time: $61.5 \%$ in the first 3 months and $82.0 \%$ by the first year. ${ }^{37}$ Notably, persistence with insulin therapy was influenced by the type of basal insulin (Gla-100 65\%, insulin detemir 53\%, and NPH insulin 59\% $)^{38}$ as well as the method of insulin administration (Gla-100 by pen $70.6 \%$; Gla- 100 by vial and syringe $62.9 \%$ ). ${ }^{40}$

\section{Dosing inflexibility}

Long-acting basal insulins (Gla-100 and insulin detemir) are usually administered once daily, while NPH insulin may be administered once or twice daily. Basal insulins must be administered at the same time every day. For some patients, this inflexibility of dosing time is a major inconvenience. Dosing time inflexibility often necessitates lifestyle changes to accommodate the prescribed dosing schedule and may reduce adherence to therapy. ${ }^{16,17,19}$ Lifestyle factors (eg, "too busy," "travelling," "skipped meals," and "stress or emotional problems") are commonly cited by physicians and patients as reasons for nonadherence to insulin therapy. ${ }^{21}$

\section{Economic barriers}

While missed and mistimed insulin doses are often unintentional, dose reductions are often made on purpose. ${ }^{41}$ Some patients may intentionally reduce their insulin dose due to the fear of hypoglycemia, ${ }^{20}$ while others may do so due to the high cost of basal insulin therapy. Cost is an important barrier in this region ${ }^{22}$ where a significant proportion of patients may not have the financial resources to continue with insulin therapy after several months. On the top of the cost of basal insulin analogs, glucometers and glucose test strips that are required for self-monitoring of blood glucose are out-of-pocket expenses and likely to be too expensive for patients in many parts of Asia (Table 2).

\section{Addressing the unmet needs in basal insulin therapy \\ Advances in basal insulin formulations}

Attributes of the ideal basal insulin

Ideally, basal insulin therapy should resemble physiological basal insulin supply as closely as possible - a flat and 
prolonged activity profile that constantly delivers insulin at steady levels to meet basal metabolic needs. A flat pharmacokinetic profile carries less risk of hypoglycemia, while a long duration of action allows for greater flexibility in terms of dosing time.

Current long-acting basal insulin options, Gla-100 and insulin detemir, have a relatively flat and extended time-action profile, providing significant advantages over the earlier intermediate-acting agent, NPH insulin. Unfortunately, the search for the ideal basal insulin has not ended. Both Gla-100 and insulin detemir still register a peak in their time-action profiles when administered at high doses, while low doses may not be sufficient to cover the entire 24-hour dosing interval. $^{42}$ To overcome patient and physician barriers in basal insulin initiation and titration, further improvements in terms of dosing flexibility and reduced hypoglycemia risk are needed. Longer-acting insulins have been developed to address current unmet needs in basal insulin therapy, the most promising of which are new insulin glargine $300 \mathrm{U} /$ $\mathrm{mL}$ (Gla-300; a new formulation of insulin glargine) and insulin degludec.

\section{New insulin Gla-300}

Gla-300 is a new formulation of insulin glargine from the original Gla-100. Similar to Gla-100, Gla-300 is an acidic liquid formulation that precipitates at physiological $\mathrm{pH}$ following subcutaneous injection with subsequent slow redissolution. For a given insulin dose, one third of the volume of Gla-300 is required compared with Gla-100. The smaller surface area of the subcutaneous depot leads to a more constant and slower release of insulin over time (onset of action $=6$ hours [Gla-300] vs 3 hours [Gla-100]), resulting in a more stable and prolonged time-action profile (duration of action $=36$ hours [Gla-300] vs 24 hours [Gla-100]) that better approximates physiological basal insulin. ${ }^{43}$

Results from large multinational randomized controlled trials investigating the glycemic effects of Gla-300 compared with Gla-100 were promising. Three-phase 3 trials (EDITION 1, 2, and 3) assessed glycemic control in adult participants with type 2 diabetes who were randomized to receive once-daily injections of either Gla-300 or Gla-100 for 6 months. While HbA1c reduction was comparable in both treatment groups, all 3 trials reported lower incidences of nocturnal hypoglycemia in patients with diabetes treated with Gla-300. ${ }^{44-46}$ Six-month extension studies of the EDITION trials demonstrated sustained glycemic control and lower rates of nocturnal hypoglycemia in patients with type 2 diabetes treated with Gla-300..$^{47,48}$ Evaluation of Gla-300 in an Asian population with type 2 diabetes mellitus (EDITION JP 2) also demonstrated comparable glycemic control and a lower incidence of nocturnal hypoglycemia compared with Gla-100. ${ }^{49}$ Although head-to-head clinical trials comparing Gla-300 with available basal insulin therapies other than Gla-100 have not been conducted, the results of a network meta-analysis suggested that Gla-300 provides glycemic control compared with NPH insulin, insulin detemir, and insulin degludec and is associated with a significantly lower risk of nocturnal hypoglycemia compared with NPH insulin. ${ }^{50}$ Nevertheless, randomized controlled trials designed for the direct comparison of Gla-300 with insulin detemir and NPH insulin are necessary to confirm these findings.

Dosing interval flexibility of Gla-300 was investigated in a 3-month substudy of people with type 2 diabetes from EDITION 1 and EDITION 2. Reduction in HbA1c and incidence of hypoglycemia was comparable in both the fixed-dosing (24-hour intervals) and flexible-dosing ( $24 \pm 3$ hour intervals) treatment groups, suggesting comparable efficacy and safety when occasional flexibility in dosing timing for Gla-300 was allowed. ${ }^{51}$

\section{Insulin degludec}

Insulin degludec is an insulin analog with a modified B-chain. The pharmaceutical formulation of insulin degludec contains soluble and stable dihexamers that reorganize to form multihexamer chains following subcutaneous administration. The long multihexamers gradually disassemble into insulin degludec monomers that are steadily released from the subcutaneous depot and absorbed into the systemic circulation. These properties give insulin degludec a prolonged duration of action ( $>42$ hours) with a long half-life ( 25 hours). ${ }^{52}$

The glycemic effects of insulin degludec compared with Gla-100 have been investigated in several large multinational clinical trials. Phase 3 open-label trials (BEGIN) have demonstrated similar efficacy of once-daily insulin degludec compared with once-daily Gla-100 in reducing HbA1c levels in people with type 2 diabetes who had previously been treated with only oral antidiabetic agents. ${ }^{53,54}$ Although overall confirmed hypoglycemia rates were similar in patients treated with insulin degludec compared with Gla-100, the frequency of nocturnal hypoglycemia was significantly lower with insulin degludec than with Gla-100. ${ }^{53,54}$ A phase 3 trial carried out exclusively in insulin-naïve Asian patients with type 2 diabetes also demonstrated efficacy and tolerability of once-daily insulin degludec in this population with a significantly lower rate of overall confirmed hypoglycemia compared with Gla-100 in the maintenance period (weeks 
16-26). ${ }^{55}$ However, no significant difference in the rate of nocturnal hypoglycemia between insulin degludec and Gla100 was observed in the Asian phase 3 trial. ${ }^{55}$ Considering the long duration of action of insulin degludec, the possibility of a 3-times-weekly dosing regimen with insulin degludec was explored. Unfortunately, results of a randomized trial demonstrated inferior glycemic control and increased risk of hypoglycemia when adults with type 2 diabetes administered insulin degludec 3 times a week compared with Gla-100 administered once a day. ${ }^{56}$

Dosing interval flexibility of insulin degludec has been investigated in people with type 2 diabetes. When patients were prescribed a rotating morning and evening dosing schedule that created an 8- to 40-hour interval between insulin degludec doses, HbAlc reduction and safety outcomes were noninferior compared with Gla-100 administered at the same time every day. ${ }^{57}$ The efficacy and safety of a flexible dosing regimen allow some flexibility in the time of dosing on occasions where dosing at fixed timings is not possible or convenient for patients.

\section{Clinical potential of new basal insulins}

Currently, the most common insulins administered for basal insulin therapy are the intermediate-acting NPH insulin and long-acting Gla-100. Initial clinical trials demonstrated comparable glucose-lowering efficacy for Gla-100 versus NPH insulin, but with a lower risk of hypoglycemia for Gla$100{ }^{58,59}$ However, real-world comparisons have provided evidence of better overall glycemic control with Gla-100 versus NPH insulin due to the greater incidence of hypoglycemia in patients receiving NPH insulin. ${ }^{60}$ Thus, even though the efficacies of the new long-acting insulins, Gla-300 and insulin degludec, in reducing $\mathrm{HbA} 1 \mathrm{c}$ levels were demonstrated to be comparable with Gla-100 in clinical trials, ${ }^{44-49,53-55}$ the lower risk of nocturnal hypoglycemia is likely to allow more aggressive titration for tighter glycemic control in real-life clinical practice. The Gla-300 formulation, which comprises the same insulin glargine molecule as Gla-100, is expected to have a similar safety profile with a neutral effect on cardiovascular outcomes and cancers. ${ }^{61}$ Indeed, no new safety signals were seen in the pivotal Gla-300 trials, ${ }^{44-49}$ and long-term safety studies were not required by regulatory authorities for its approval. The possibility of dosing interval flexibility to match patients' lifestyle should also translate into tangible benefits such as improved patient adherence.

Both Gla-300 and insulin degludec have been approved in the USA and European Union and in several countries in Asia (Japan, Korea, Hong Kong, India, Taiwan, Thailand, and the
Philippines). In addition, Gla-300 has also been approved in Malaysia and Singapore and may soon be available in other countries in Asia. The approval and availability of Gla-300 and insulin degludec will expand current basal insulin therapy options in the region. Several patient subgroups may benefit particularly from the improved basal long-acting insulins: 1) patients who are at an increased risk of hypoglycemia (eg, elderly patients and patients with chronic kidney disease and/or cardiovascular disease); 2) patients who need some dosing flexibility (eg, those who work shifts or have irregular schedules); and 3) patients who require high doses of basal insulin (>1 U/kg/day) - particularly for Gla-300, higher doses can be administered in smaller volumes, thus causing less injection discomfort.

\section{Overcoming patient and physician barriers \\ Improving patient education about diabetes and insulin therapy}

In Asia, the lack of diabetes education has been found to be strongly associated with persistent poor glycemic control. ${ }^{62}$ Physicians are encouraged to educate patients on the progressive nature of type 2 diabetes from the time of diagnosis and reinforce the danger of poor glycemic control throughout the therapeutic journey. For patients who doubt the actual benefits of insulin (due to either misconceptions or hearsay), positive testimonials from peer-based support programs may help to counter negative attitudes and encourage prompt therapeutic intervention.

Awareness of the risk of hypoglycemia is important for the safe use of insulin. In Asia, many physicians may find it difficult to thoroughly educate patients on safe insulin utilization during the limited time that they spend with each patient. Thus, diabetes support teams are crucial to assist physicians in the educational task on the proper use of insulin and to teach patients to recognize the symptoms of hypoglycemia and how to treat it if it occurs. Patient education through consultation with nurses, dietitians, or diabetes educators can significantly improve insulin use and glycemic control without having a major impact on healthcare costs. ${ }^{63}$ Improved patient support from providers, diabetes management teams, and diabetes support programs (eg, $\mathrm{COACH}^{\circledR}$ for Gla-300 users $)^{78}$ are also important to encourage better adherence and persistence with insulin therapy. Further studies are needed to demonstrate the value of patient support programs in improving diabetes outcomes in Asia.

Access to diabetes support teams may be limited in many places in Asia (Table 2). To encourage patients to play a more 
active role in their treatment, patient-physician communication is important. Communication tools (eg, telephone consultations) could be enhanced to improve interactions between healthcare professionals and patients.

\section{Mitigating needle-phobia}

Anticipated pain and difficulty of regular insulin injections are common patient barriers to insulin therapy. ${ }^{18,20}$ In such cases, in-clinic demonstrations of insulin injections and use of glucose monitors may help to equip patients with the necessary skills. The first injection experience with a healthcare provider may also improve the perception of insulin dosing and thus mitigate concerns of pain and difficulty in administering insulin.

Physicians may also consider prescribing prefilled insulin pens, which make injections simple and straightforward compared with the traditional use of vial and syringe.$^{19}$ In a survey of people with diabetes and healthcare professionals with experience in prescribing insulin pens, the optimized SoloSTAR $^{\circledR}$ pen (Sanofi-Aventis, Paris, France) used for administering Gla-300 was ranked first as being the "easiest to inject yourself," "easiest to use overall," and "the least effort required to push plunger" out of 3 other disposable prefilled insulin injector pens (SoloSTAR ${ }^{\circledR}$ [Gla-100], FlexPen $^{\circledR}$ [insulin aspart; Novo Nordisk A/S Bagsværd, Denmark], and KwikPen ${ }^{\circledR}$ [insulin lispro; Eli Lilly \& Co, Indianapolis, IN, USA]). ${ }^{64}$ Given that insulin pens are associated with less needle-phobia and that ease of injecting insulin contributes to increased patient compliance with therapy, ${ }^{65}$ the selection of an appropriate insulin administration device according to patients' preference is important to improve adherence and persistence with basal insulin therapy. However, this needs to be balanced against the higher cost of insulin pen devices.

\section{Encouraging patient self-titration}

In the face of increasingly stretched healthcare resources and a growing diabetes patient population, dependence on physicians for insulin dose adjustments needs to be reduced. Patient-led titration (where patients adjust insulin doses themselves) using a simple titration algorithm can achieve near-target blood glucose levels with a low incidence of hypoglycemia that is comparable with physician-managed titration. ${ }^{66}$ Although insulin self-titration is commonly practiced in the West, it is far less common in Asia. Nonetheless, the multinational ATLAS study demonstrated that Asian patients can effectively self-titrate Gla-100 doses to achieve glycemic targets. ${ }^{66}$ More importantly, self-adjustment of insulin doses was a strong predictor for achieving $\mathrm{HbA} 1 \mathrm{c}<53 \mathrm{mmol} / \mathrm{mol}$
$(<7 \%)$ in Asia. ${ }^{67}$ Consequently, encouraging patient selftitration not only reduces the burden of care on physicians and healthcare systems, but also allows for timelier uptitration of insulin and accommodation of doses to the real-life activities of patients for better glycemic control.

\section{Bridging infrastructural gaps}

Asia lags behind Western countries in insulin initiation and utilization, particularly in developing Asian nations where diabetes is still primarily managed by general practitioners. ${ }^{67}$ Despite clear indications of poor glycemic control from clinical assessments, appropriate actions are frequently not taken by physicians to improve glycemic control. ${ }^{67}$ Deviations from recommended guidelines may stem from poor physician knowledge of diabetes management or lack of awareness of the types and availability of different insulins. To improve the quality of diabetes care in Asia, more physician support and training in using basal insulins and greater medical education are necessary to close knowledge and practice gaps between primary healthcare providers and specialist care.

Basal insulin analogs and consumables (syringes, needles, insulin pens, glucometers, and glucose test strips) are not subsidized or covered by health insurance in most parts of Asia (Table 2). Financial constraints may discourage patients from starting on or persisting with therapy if they are unable to afford these out-of-pocket payments. ${ }^{68}$ However, the higher prescription costs of long-acting insulins may in reality be offset by reductions in healthcare and hospitalization costs arising from diabetes complications (eg, comorbidities or hypoglycemia). The cost-effectiveness of long-acting insulins has been demonstrated in countries with different levels of healthcare resources. ${ }^{69}$ Hypoglycemic events and mortality were substantially lower among users of Gla-100 than among NPH insulin users. ${ }^{70,71}$ Given that Asian patients tend to develop diabetes at a younger age and are at an increased risk of complications, ${ }^{72}$ the cost-effectiveness of long-acting insulin analog therapy is likely to be even greater in Asia. As the health gains from better glycemic control will likely reduce resource utilization and lower the national economic burden of diabetes-related complications, healthcare authorities are encouraged to consider ways to help reduce or subsidize costs of long-acting insulin analogs and the necessary consumables.

\section{Conclusion}

Delays in insulin initiation, insufficient dose titration, and poor adherence are ongoing challenges in basal insulin therapy in Asia. Although certain unmet needs, such as 
reduced hypoglycemia risk and dosing flexibility, may be partly addressed by newer long-acting insulin analogs (Gla-300 and insulin degludec), more can certainly be done to overcome patient and physician barriers to insulin therapy. First, patients and healthcare providers should be educated on the initiation and active titration of basal insulin therapy at the early stages of type 2 diabetes; second, further research is needed to determine the best patient support model to improve diabetes outcomes in Asia; and third, accessibility to long-acting insulin analogs should be improved for patients who have severe financial constraints or who reside in less developed regions. Prolonged hyperglycemia can lead to serious long-term complications in patients with diabetes, ultimately increasing the burden on personal and health system resources. An integrated public health approach is crucial to address these unmet needs and to bring down the high socioeconomic and human costs of living with diabetes in Asia.

\section{Acknowledgment}

Manuscript drafting assistance and editorial support were provided by Bao Hui Lee and Geraldine Toh (Tech Observer Asia Pacific, Singapore) and were funded by Sanofi-Aventis. All authors have contributed equally to this work.

\section{Disclosure}

WB Chan has received honoraria and served on the advisory boards of AstraZeneca and Boehringer Ingelheim. S Goh has served on the local/regional advisory boards of Sanofi, AstraZeneca, Merck Sharp \& Dohme, and Boehringer Ingelheim. IT Isip-Tan has received sponsorship from Sanofi and Novo Nordisk to attend medical conferences and has received honoraria from Sanofi for presentations at conferences and round table discussions. SW Mudjanarko has served as a scientific speaker for Sanofi, Novo Nordisk, and Eli Lilly. S Bajpai and MA Mabunay are employees of Sanofi, Singapore. P Bunnag has served on the advisory panel and as a speaker for Abbott, AstraZeneca, Boehringer Ingelheim, Eli Lilly, Merck Sharp \& Dohme, Novartis, Novo Nordisk, Pfizer, Sanofi, and Takeda and served as a speaker for Thai Otsuka. JF Chen and TTH Vu have no relevant relationships to disclose. The authors report no other conflicts of interest in this work.

\section{References}

1. International Diabetes Federation. Global Guideline for Type 2 Diabetes; 2015. Available from: http://www.idf.org/webdata/docs/IDF\%20 GGT2D.pdf.
2. Ministry of Public Health Thailand. Diabetes Clinical Practice Guidelines; 2013. Available from: http://www.dms.moph.go.th/dmsweb/ cpgcorner/54-22.pdf.

3. Ministry of Health Malaysia. Clinical Practice Guidelines for the Management of Type 2 Diabetes Mellitus (5th Edition). 2015; Available from: http://www.acadmed.org.my/. Accessed May 3, 2017.

4. Department of Health (Hong Kong Special Administrative Region). Hong Kong Reference Framework for Diabetes Care for Adults in Primary Care Settings; 2013. Available from: http://www.pco.gov.hk/ english/resource/files/RF_DM_full.pdf.

5. UNITE for Diabetes Philippines. Philippine Practice Guidelines on the Diagnosis and Management of Diabetes Mellitus; 2014. Available from: http://endo-society.org.ph/v5/wp-content/uploads/2013/06/DiabetesUnited-for-Diabetes-Phil.pdf.

6. DAROC. DAROC Clinical Practice Guidelines for Diabetes Care2015. Taiwan: Diabetes Association of the Republic of China; 2015.

7. Ministry of Health Singapore. Clinical Practice Guidelines - Diabetes Mellitus; 2014. Available from: https://www.moh.gov.sg/content/dam/ moh_web/HPP/Doctors/cpg_medical/current/2014/diabetes_mellitus/ cpg_Diabetes\%20Mellitus\%20Booklet\%20-\%20Jul\%202014.pdf.

8. Indonesian Society of Endocrinology. Consensus on Management and Prevention of Type 2 Diabetes Mellitus in Indonesia; 2011. Available from: http://www.pbpapdi.org/images/file_guidelines/12_Konsensus $\% 20$ Pengelolaaln $\% 20$ dan $\% 20$ Pencegahan $\% 20$ Diabets $\% 20$ Melitus\%20Tipe\%202\%20di\%20Indonesia\%202006.PDF.

9. Khunti K, Damci T, Meneghini L, Pan CY, Yale JF; SOLVE Study Group. Study of Once Daily Levemir (SOLVETM): insights into the timing of insulin initiation in people with poorly controlled type 2 diabetes in routine clinical practice. Diabetes Obes Metab. 2012;14(7):654-661.

10. Jones S, Benroubi M, Castell C, et al. Characteristics of patients with type 2 diabetes mellitus initiating insulin therapy: baseline data from the INSTIGATE study. Curr Med Res Opin. 2009;25(3):691-700.

11. Tsai ST, Pathan F, Ji L, et al. First insulinization with basal insulin in patients with Type 2 diabetes in a real-world setting in Asia. J Diabetes. 2011;3(3):208-216.

12. Ji L, Tsai ST, Lin J, Bhambani S. National variations in comorbidities, glycosylated hemoglobin reduction, and insulin dosage in Asian patients with type 2 diabetes: the FINE-Asia registry. Diabetes Ther. Epub 2015 Oct 14.

13. Calvert MJ, McManus RJ, Freemantle N. Management of type 2 diabetes with multiple oral hypoglycaemic agents or insulin in primary care: retrospective cohort study. Br J Gen Prac. 2007;57(539):455-460.

14. Kostev K, Rathmann W. Changes in time to insulin initiation in type 2 diabetes patients: a retrospective database analysis in Germany and UK (2005-2010). Prim Care Diabetes. 2013;7(3):229-233.

15. Ji L, Zhang P, Weng J, et al. Observational Registry of Basal Insulin Treatment (ORBIT) in patients with type 2 diabetes uncontrolled by oral hypoglycemic agents in China-study design and baseline characteristics. Diabetes Technol Ther. 2015;17(10):735-744.

16. Peyrot M, Rubin RR, Khunti K. Addressing barriers to initiation of insulin in patients with type 2 diabetes. Prim Care Diabetes. 2010;4(Supp1 1):S11-S18.

17. Polonsky WH, Fisher L, Guzman S, Villa-Caballero L, Edelman SV. Psychological insulin resistance in patients with type 2 diabetes: the scope of the problem. Diabetes Care. 2005;28(10):2543-2545.

18. Wong S, Lee J, Ko Y, Chong MF, Lam CK, Tang WE. Perceptions of insulin therapy amongst Asian patients with diabetes in Singapore. Diabet Med. 2011;28(2):206-211.

19. Brod M, Kongso JH, Lessard S, Christensen TL. Psychological insulin resistance: patient beliefs and implications for diabetes management. Qual Life Res. 2009;18(1):23-32.

20. Larkin ME, Capasso VA, Chen CL, et al. Measuring psychological insulin resistance: barriers to insulin use. Diabetes Educ. 2008;34(3):511-517.

21. Peyrot M, Barnett AH, Meneghini LF, Schumm-Draeger PM. Insulin adherence behaviours and barriers in the multinational Global Attitudes of Patients and Physicians in Insulin Therapy study. Diabet Med. 2012;29(5):682-689. 
22. Beran D, Higuchi M. Delivering diabetes care in the Philippines and Vietnam: policy and practice issues. Asia Pac J Public Health. 2013;25(1): 92-101.

23. Home P, Naggar NE, Khamseh M, et al. An observational noninterventional study of people with diabetes beginning or changed to insulin analogue therapy in non-Western countries: the A1 chieve study. Diabetes Res Clin Pract. 2011;94(3):352-363.

24. Ahren B. Avoiding hypoglycemia: a key to success for glucose-lowering therapy in type 2 diabetes. Vasc Health Risk Manag. 2013;9:155-163.

25. Amiel SA, Dixon T, Mann R, Jameson K. Hypoglycaemia in Type 2 diabetes. Diabet Med. 2008;25(3):245-254.

26. Brunton SA. Nocturnal hypoglycemia: answering the challenge with long-acting insulin analogs. MedGenMed. 2007;9(2):38.

27. Zoungas S, Patel A, Chalmers J, et al. Severe hypoglycemia and risks of vascular events and death. NEngl J Med. 2010;363(15):1410-1418

28. Fu H, Curtis BH, Xie W, Festa A, Schuster DP, Kendall DM. Frequency and causes of hospitalization in older compared to younger adults with type 2 diabetes in the United States: a retrospective, claims-based analysis. J Diabetes Complications. 2014;28(4):477-481.

29. Garber AJ. Hypoglycaemia: a therapeutic concern in type 2 diabetes The Lancet. 2012;379(9833):2215-2216.

30. Rosenstock J, Fonseca V, Schinzel S, Dain MP, Mullins P, Riddle M Reduced risk of hypoglycemia with once-daily glargine versus twice-daily NPH and number needed to harm with NPH to demonstrate the risk of one additional hypoglycemic event in type 2 diabetes: evidence from a longterm controlled trial. J Diabetes Complications. 2014;28(5):742-749.

31. Haukka J, Hoti F, Erasto P, Saukkonen T, Makimattila S, Korhonen P. Evaluation of the incidence and risk of hypoglycemic coma associated with selection of basal insulin in the treatment of diabetes: a Finnish register linkage study. Pharmacoepidemiol Drug Saf. 2013;22(12):1326-1335.

32. Little S, Shaw J, Home P. Hypoglycemia rates with basal insulin analogs. Diabetes Technol Ther. 2011;13(Suppl 1):S53-S64.

33. Nathan DM, Buse JB, Davidson MB, et al. Management of hyperglycemia in type 2 diabetes: a consensus algorithm for the initiation and adjustment of therapy: a consensus statement from the American Diabetes Association and the European Association for the Study of Diabetes. Diabetes Care. 2006;29(8):1963-1972.

34. Garber AJ, Abrahamson MJ, Barzilay JI, et al. American Association of Clinical Endocrinologists' comprehensive diabetes management algorithm 2013 consensus statement--executive summary. Endocr Pract. 2013;19(3):536-557

35. Mashitani T, Hayashino Y, Okamura S, et al. Patient-reported adherence to insulin regimen is associated with glycemic control among Japanese patients with type 2 diabetes: Diabetes Distress and Care Registry at Tenri (DDCRT 3). Diabetes Res Clin Pract. 2013;100(2):189-194.

36. Ho PM, Rumsfeld JS, Masoudi FA, et al. Effect of medication nonadherence on hospitalization and mortality among patients with diabetes mellitus. Arch Intern Med. 2006;166(17):1836-1841.

37. Ascher-Svanum H, Lage MJ, Perez-Nieves M, et al. Early discontinuation and restart of insulin in the treatment of type 2 diabetes mellitus. Diabetes Ther. 2014;5(1):225-242.

38. Pscherer S, Chou E, Dippel FW, Rathmann W, Kostev K. Treatment persistence after initiating basal insulin in type 2 diabetes patients: a primary care database analysis. Prim Care Diabetes. 2015;9(5):377-384

39. Patrick AR, Fischer MA, Choudhry NK, et al. Trends in insulin initiation and treatment intensification among patients with type 2 diabetes. J General Intern Med. 2014;29(2):320-327.

40. Wei W, Pan C, Xie L, Baser O. Real-world insulin treatment persistence among patients with type 2 diabetes. Endocr Pract. 2014;20(1):52-61.

41. Brod M, Rana A, Barnett AH. Adherence patterns in patients with type 2 diabetes on basal insulin analogues: missed, mistimed and reduced doses. Curr Med Res Opin. 2012;28(12):1933-1946.

42. Heise T, Pieber TR. Towards peakless, reproducible and long-acting insulins. An assessment of the basal analogues based on isoglycaemic clamp studies. Diabetes Obes Metab. 2007;9(5):648-659.
43. Becker RH, Dahmen R, Bergmann K, Lehmann A, Jax T, Heise T. New insulin glargine 300 Units $\cdot \mathrm{mL}-1$ provides a more even activity profile and prolonged glycemic control at steady state compared with insulin glargine 100 Units · mL-1. Diabetes Care. 2015;38(4):637-643.

44. Riddle MC, Bolli GB, Ziemen M, et al. New insulin glargine 300 units/ $\mathrm{mL}$ versus glargine 100 units/mL in people with type 2 diabetes using basal and mealtime insulin: glucose control and hypoglycemia in a 6-month randomized controlled trial (EDITION 1). Diabetes Care. 2014;37(10):2755-2762.

45. Yki-Jarvinen H, Bergenstal R, Ziemen M, et al. New insulin glargine 300 units $/ \mathrm{mL}$ versus glargine 100 units $/ \mathrm{mL}$ in people with type 2 diabetes using oral agents and basal insulin: glucose control and hypoglycemia in a 6-month randomized controlled trial (EDITION 2). Diabetes Care. 2014;37(12):3235-3243.

46. Bolli GB, Riddle MC, Bergenstal RM, et al. New insulin glargine 300 $\mathrm{U} / \mathrm{ml}$ compared with glargine $100 \mathrm{U} / \mathrm{ml}$ in insulin-naive people with type 2 diabetes on oral glucose-lowering drugs: a randomized controlled trial (EDITION 3). Diabetes Obes Metab. 2015;17(4):386-394.

47. Riddle MC, Yki-Jarvinen H, Bolli GB, et al. One-year sustained glycaemic control and less hypoglycaemia with new insulin glargine $300 \mathrm{U} / \mathrm{ml}$ compared with $100 \mathrm{U} / \mathrm{ml}$ in people with type 2 diabetes using basal plus meal-time insulin: the EDITION 1 12-month randomized trial, including 6-month extension. Diabetes Obes Metab. 2015;17(9):835-842.

48. Yki-Jarvinen H, Bergenstal RM, Bolli GB, et al. Glycaemic control and hypoglycaemia with new insulin glargine $300 \mathrm{U} / \mathrm{ml}$ versus insulin glargine $100 \mathrm{U} / \mathrm{ml}$ in people with type 2 diabetes using basal insulin and oral antihyperglycaemic drugs: the EDITION 2 randomized 12-month trial including 6-month extension. Diabetes Obes Metab. 2015;17(12):1142-1149.

49. Terauchi Y, Koyama M, Cheng X, et al. New insulin glargine $300 \mathrm{U} /$ $\mathrm{ml}$ versus glargine $100 \mathrm{U} / \mathrm{ml}$ in Japanese people with type 2 diabetes using basal insulin and oral antihyperglycaemic drugs: glucose control and hypoglycaemia in a randomized controlled trial (EDITION JP 2). Diabetes Obes Metab. 2016;18(4):366-374.

50. Freemantle N, Chou E, Frois C, et al. Safety and efficacy of insulin glargine $300 \mathrm{u} / \mathrm{mL}$ compared with other basal insulin therapies in patients with type 2 diabetes mellitus: a network meta-analysis. $B M J$ Open. 2016;6(2):e009421.

51. Riddle MC, Bolli GB, Home PD, et al. Efficacy and safety of flexible versus fixed dosing intervals of insulin glargine $300 \mathrm{U} / \mathrm{mL}$ in people with type 2 diabetes. Diabetes Technol Ther. 2016;18:252-257.

52. Heise T, Nosek L, Bottcher SG, Hastrup H, Haahr H. Ultra-long-acting insulin degludec has a flat and stable glucose-lowering effect in type 2 diabetes. Diabetes Obes Metab. 2012;14(10):944-950.

53. Zinman B, Philis-Tsimikas A, Cariou B, et al. Insulin degludec versus insulin glargine in insulin-naive patients with type 2 diabetes: a 1-year, randomized, treat-to-target trial (BEGIN Once Long). Diabetes Care. 2012;35(12):2464-2471

54. Rodbard HW, Cariou B, Zinman B, et al. Comparison of insulin degludec with insulin glargine in insulin-naive subjects with Type 2 diabetes: a 2-year randomized, treat-to-target trial. Diabet Med. 2013;30(11): 1298-1304.

55. Onishi Y, Iwamoto Y, Yoo SJ, Clauson P, Tamer SC, Park S. Insulin degludec compared with insulin glargine in insulin-naive patients with type 2 diabetes: a 26-week, randomized, controlled, Pan-Asian, treatto-target trial. J Diabetes Investig. 2013;4(6):605-612.

56. Zinman B, DeVries JH, Bode B, et al. Efficacy and safety of insulin degludec three times a week versus insulin glargine once a day in insulin-naive patients with type 2 diabetes: results of two phase 3,26 week, randomised, open-label, treat-to-target, non-inferiority trials. Lancet Diabetes Endocrinol. 2013;1(2):123-131.

57. Meneghini L, Atkin SL, Gough SC, et al. The efficacy and safety of insulin degludec given in variable once-daily dosing intervals compared with insulin glargine and insulin degludec dosed at the same time daily: a 26-week, randomized, open-label, parallel-group, treat-to-target trial in individuals with type 2 diabetes. Diabetes Care. 2013;36(4):858-864. 
58. Yki-Jarvinen H, Dressler A, Ziemen M; HOE 901/3002 Study Group. Less nocturnal hypoglycemia and better post-dinner glucose control with bedtime insulin glargine compared with bedtime NPH insulin during insulin combination therapy in type 2 diabetes. Diabetes Care. 2000;23(8):1130-1136.

59. Rosenstock J, Dailey G, Massi-Benedetti M, Fritsche A, Lin Z, Salzman A. Reduced hypoglycemia risk with insulin glargine: a meta-analysis comparing insulin glargine with human NPH insulin in type 2 diabetes. Diabetes Care. 2005;28(4):950-955.

60. Fiesselmann A, Wiesner T, Fleischmann H, Bramlage P. Real-world therapeutic benefits of patients on insulin glargine versus NPH insulin. Acta Diabetol. 2016;53:717-726.

61. ORIGIN Trial Investigators, Gerstein HC, Bosch J, et al. Basal insulin and cardiovascular and other outcomes in dysglycemia. $N$ Engl J Med. 2012;367(4):319-328.

62. Yin J, Yeung R, Luk A, et al. Gender, diabetes education, and psychosocial factors are associated with persistent poor glycemic control in patients with type 2 diabetes in the Joint Asia Diabetes Evaluation (JADE) program. J Diabetes. 2016;8(1):109-119.

63. Gagliardino JJ, Aschner P, Baik SH, et al. Patients' education, and its impact on care outcomes, resource consumption and working conditions: data from the International Diabetes Management Practices Study (IDMPS). Diabetes Metab. 2012;38(2):128-134.

64. Klonoff D, Nayberg I, Erbstein F, Cali A, Brulle-Wohlhueter C, Haak T. Usability of the Gla-300 injection device compared with three other commercialized disposable insulin pens: results of an interview-based survey. J Diabetes Sci Technol. 2015;9(4):936-938.

65. Anderson BJ, Redondo MJ. What can we learn from patient-reported outcomes of insulin pen devices? J Diabetes Sci Technol. 2011;5(6): 1563-1571.

66. Garg SK, Admane K, Freemantle N, et al. Patient-led versus physician-led titration of insulin glargine in patients with uncontrolled type 2 diabetes: a randomized multinational ATLAS study. Endocr Pract. 2015;21(2):143-157.

67. Chan JC, Gagliardino JJ, Baik SH, et al. Multifaceted determinants for achieving glycemic control: the International Diabetes Management Practice Study (IDMPS). Diabetes Care. 2009;32(2):227-233.

68. Higuchi M. Access to diabetes care and medicines in the Philippines. Asia Pac J Public Health. 2010;22(3 Suppl):96S-102S.
69. Home P, Baik SH, Galvez GG, Malek R, Nikolajsen A. An analysis of the cost-effectiveness of starting insulin detemir in insulin-naive people with type 2 diabetes. J Med Econ. 2015;18(3):230-240.

70. Strandberg AY, Hoti FJ, Strandberg TE, Christopher S, Haukka J, Korhonen P. All-cause and cause-specific mortality among users of basal insulins NPH, detemir, and glargine. PLoS One. 2016;11(3): e0151910.

71. Rawdaree P, Sarinnapakorn V, Pattanaungkul S, Khovidhunkit W, Tannirandorn P, Peerapatdit T. A prospective, longitudinal, multicenter, observational study to assess insulin treatment patterns in diabetic patients in Thailand: results from the TITAN Study. J Med Assoc Thai. 2014;97(11):1140-1150.

72. Ramachandran A, Snehalatha C, Shetty AS, Nanditha A. Trends in prevalence of diabetes in Asian countries. World J Diabetes. 2012;3(6): $110-117$.

73. International Diabetes Federation. IDF Diabetes Atlas. 7th ed; 2015. Available from: http://www.idf.org/diabetesatlas. Accessed May 2, 2017.

74. Yan BP, Zhang Y, Kong AP, et al. Borderline ankle-brachial index is associated with increased prevalence of micro- and macrovascular complications in type 2 diabetes: a cross-sectional analysis of 12,772 patients from the Joint Asia Diabetes Evaluation Program. Diab Vasc Dis Res. 2015;12(5):334-341.

75. Jimeno CA, Sobreprena LM, Mirasol RC. DiabCare 2008: survey on glycaemic control and the status of diabetes care and complications among patients with type 2 diabetes mellitus in the Philippines. Philipp J Internal Med. 2012;50:15-22.

76. Yu NC, Su HY, Chiou ST, et al. Trends of ABC control 2006-2011: a National Survey of Diabetes Health Promotion Institutes in Taiwan. Diabetes Res Clin Pract. 2013;99(2):112-119.

77. Kosachunhanun N, Benjasuratwong Y, Mongkolsomlit S, et al. Thailand diabetes registry project: glycemic control in Thai type 2 diabetes and its relation to hypoglycemic agent usage.JMedAssoc Thai. 2006;89(Suppl 1): S66-S71.

78. Toujeo COACH - support that's individual to each Toujeo patient. [webpage on the Internet]. Available from https://www.toujeopro.com/ toujeo-coach. Accessed November 11, 2017.

\section{Publish your work in this journal}

Diabetes, Metabolic Syndrome and Obesity: Targets and Therapy is an international, peer-reviewed open-access journal committed to the rapid publication of the latest laboratory and clinical findings in the fields of diabetes, metabolic syndrome and obesity research. Original research, review, case reports, hypothesis formation, expert opinion and commentaries are all considered for publication. The manuscript management system is completely online and includes a very quick and fair peer-review system, which is all easy to use. Visit http://www.dovepress.com/testimonials.php to read real quotes from published authors. 